1

\title{
Increasing frequency of hospital admissions for retinal detachment and vitreo-retinal surgery in England 2000-2018
}

\section{Increasing hospital admissions for retinal surgery}

\author{
Haifa A Madi ${ }^{1}$ MBChB BSc FRCOphth, Johannes Keller ${ }^{2}$ FRCOphth
}

1 Brighton and Sussex University Hospitals NHS Trust, Sussex Eye Hospital, Eastern Road, Brighton BN2 5BF, United Kingdom

2 University Hospitals Bristol and Weston NHS Foundation Trust, Bristol Eye Hospital, Lower Maudlin Street, Bristol BS1 2LX, United Kingdom

Correspondence to: Mr Johannes Keller, Bristol Eye Hospital, email: johannes.keller@uhbw.nhs.uk

\section{Conflict of interest}

The authors declare no potential of conflicts of interest with respect to the research, authorship, and/or publication of this article.

\section{Keywords}

Rhegmatogenous retinal detachment, tractional retinal detachment, pars plana vitrectomy, scleral buckling 


\section{Abstract}

27 Objectives To analyse the changes in reported frequency of retinal detachment admissions and vitreo-retinal surgery procedures performed between 2000-2018 in England. To obtain information useful to contribute towards the planning of service delivery.

Methods Analysis of England's Hospital Episode Statistics from the Health and Social Care Information Centre and population data from the United Kingdom's Office for National Statistics.

Results Episodes of "retinal detachments with breaks" increased year on year from 3,447 detachment" increased from $290(0.6 / 100 M)$ to $910(1.6 / 100 M)$ in the same period $(p<0.0001)$. The number of reported pars plana vitrectomies irrespective of indication increased over fourfold from 5,761 to 26,900 ( $p<0.0001$ ), while the number of scleral buckling records decreased by two thirds from 2,897 to $780(p<0.0001)$. During the same period the population of England increased from 49.2 million-55.6 million, proportionally at a slower rate than that for recorded hospital episodes. to have been increasing significantly since 2000 . This effect is more marked in cases of rhegmatogenous retinal detachment. This may be partially explained by repeat surgery in cases of recurrent retinal detachment. Other possible explanations may be increased incidence of disease (due to increased rates of cataract surgery, increasing longevity and rates of myopia), improvements local changes in methodology of hospital coding. 
Rhegmatogenous retinal detachment (RRD) is a serious ophthalmic condition where the from a retinal break. Without treatment, RRD leads to blindness in the affected eye. Advances in surgical treatment allow for the prevention of vision loss in most cases. Recent refinements in surgical technique including self-sealing small gauge vitrectomy and wide-angle viewing systems have significantly improved the ability of surgeons to treat RRD quickly and safely. recent report estimated an incidence increase from $13.4 / 100,000$ in the 1990 s to $15.4 / 100,000$ in the $2010 \mathrm{~s}^{2}$. A meta-analysis of 5 studies carried out in Europe ${ }^{3}$ estimated the average incidence of RD in the continent at $13.3 / 100,000$.

In England, all instances of hospital admission, day case intervention and emergency attendances are recorded in a database containing details of diagnoses and procedures called the Hospital Episode Statistics $(\mathrm{HES})^{4}$. Each instance of care is recorded as one episode, regardless if a given patient is treated more than once for the same condition. Diagnoses are recorded using the World Health procedures are coded with the NHS's Office for Population Census and Surveys Classification of Surgical Operations version 4 (OPCS-4). These data are identified and coded from medical records following the discharge of each patient from each episode. English NHS healthcare providers use these data to claim refund from the regional funding bodies for the care they deliver. The same data

71 are also processed and used for other purposes, such as health services delivery planning and

72 research. 
medRxiv preprint doi: https://doi.org/10.1101/2020.11.06.20214734; this version posted November 7, 2020. The copyright holder for this preprint (which was not certified by peer review) is the author/funder, who has granted medRxiv a license to display the preprint in perpetuity.

\section{It is made available under a CC-BY-NC-ND 4.0 International license .}

73

74 We set out to analyse England's HES to seek changes in trends of admission to healthcare facilities

75 for treatment of RRD from 2000 to 2018 . We also set out to study changes in frequency and type of

76 vitreo-retinal operations carried out during this period. The purpose was to gain insight into the

77 epidemiology of surgical retinal disease with the aim to inform service planning and resource

78 deployment.

79 
81 The publicly available HES Hospital Admitted Patient Care Activity records were downloaded from

82 the NHS Digital ${ }^{4}$ internet portal both for procedures and diagnosis. The reported year follows the UK

83 fiscal year which runs from April until March and is reported based on the year of period end,

84 therefore 2004 comprises the period from April 2003 until March 2004. England's population data

85 were obtained from the mid-year estimate from the Office for National Statistics ${ }^{5}$ corresponding to

86 the fiscal year where the estimate lies. For example, the mid-year estimate for 2010 was used to

87 calculate the rate of admission for the fiscal year 2010-11.

Diagnoses

The ICD-10 codes for retinal detachment with breaks (H33.0) and tractional retinal detachment

(TRD) (H33.4) were analysed separately. The code H33.0 explicitly excludes cases where the retinal

detachment was associated with diabetes which should allow for a targeted analysis of RRD. There is no similar distinction within code $\mathrm{H} 33.4$ between diabetes-related tractional detachment and other tractional pathology such as retinopathy of prematurity or proliferative vitreo-retinopathy.

94 Associated codes within the same H33.x root include codes for retinoschisis and retinal cysts H33.1, serous retinal detachment H33.2, retinal breaks without detachment H33.3. We analysed changes in H33.2 and H33.3 as comparators as they should be susceptible to variation due to population change. The code for other retinal detachments H33.5 was not analysed.

The OPCS-4 codes for interventions on the retina and the lens were studied. Records were analysed from the database of main procedure descriptor for pars plana vitrectomy (C79.2) and cataract 
scleroplasty (C54.1), imbrication of sclera (C54.2), buckling of sclera and implant (C54.3), buckling of sclera and local or encircling explant (C54.4), buckling of sclera (C54.5), other specified buckling operations for attachment of retina (54.8) and unspecified buckling operations for attachment of retina (54.9).

Additionally, as there is no nationally mandated coding record of pars plana vitrectomy in primary position for all vitrectomy operations, we built a construct adding surgical manoeuvres which require pars plana vitrectomy access to the vitreous cavity, to the vitrectomy code (C79.2). vitreous substitute into vitreous body NEC (C79.3), internal tamponade of retina using liquid (C79.6), removal of internal tamponade agent from vitreous body (C79.7), other specified operations on vitreous body (C79.8), peel of epiretinal fibroglial membrane (C80.1), peel of internal limiting membrane (C80.2), delamination of epiretinal fibrovascular membrane (C80.3), segmentation of epiretinal fibrovascular membrane (C80.4), removal of subretinal vascular membrane (C80.5), removal of subretinal membrane NEC (C80.6), other specified operations on retinal membrane (C80.8) unspecified operations on retinal membrane (C80.9), pigment epithelium translocation of retina (C83.1), macular translocation three hundred and sixty degrees (C83.2), limited macular translocation (C83.3), other specified translocation of retina (C83.8), unspecified translocation of retina (C83.9), epiretinal dissection (C84.1), excision of lesion of retina NEC (C84.2), biopsy of lesion of retina (C84.3), retinal vascular sheathotomy (C84.4), drainage of subretinal fluid through retina were not included. 
medRxiv preprint doi: https://doi.org/10.1101/2020.11.06.20214734; this version posted November 7, 2020. The copyright holder for this preprint (which was not certified by peer review) is the author/funder, who has granted medRxiv a license to display the preprint in perpetuity. It is made available under a CC-BY-NC-ND 4.0 International license.

129 cataract surgery volumes. The ratio between buckling operations and admissions for RRD was

130 calculated.

131 Consent was not required as this is a study of a database in the public domain and no patient

132 identifiable information was used. 


\section{Results}

During the business year ending 2001 there were 3,447 admissions to hospitals in England for RRD with breaks (Figure 1). This figure more than trebled with an average annual growth of $7.2 \%$ and a slope of 464.7 cases per year to 10,971 in $2018\left(R=0.98, R^{2}=0.97, p<0.001\right)$. TRDs during 2000-01 were recorded in 290 instances. These too increased steadily at an annual rate of $7.9 \%$, more than trebling in the study period to $910(R=0.93, R 2=0.87, p=<0.0001)$. By comparison, serous retinal detachments were recorded with a frequency of 3,941 in 2000 but reduced slightly throughout the study period with a regression slope of $-32.1\left(R=-0.56, R^{2}=0.32, p=0.01\right)$. Retinal breaks without a detachment were recorded at 3,141 in 2000, dropping to 1,842 in 2004 and then remaining relatively stable from 2006 with an average of 2433.1 per annum $(R=-0.25, R 2=0.06, p=0.93)$.

145 Calculating the rate of admission for the mid-year population level showed 7.0 episodes per 100,000 population for RD with breaks during 2000-01 with year-on-year increases to 19.7/100,000 in 2017-

14718 with a slope of 0.79 and $R=0.98$. The slopes for admissions for TRD ( $0.05 /$ year), serous retinal detachment (-0.12/year) and retinal breaks without detachment (-0.06/year) show little change compared to population growth.

To estimate the effect of re-admission for recurrent retinal detachment, we assumed an average RRD recurrence rate of $13.0 \%{ }^{6}$ and a single operation to repair the recurrence. Deducting these from

152 the total of admissions to estimate the value of primary retinal detachments, the regression slope is 153 reduced to 404.3 cases per annum of growth (Figure 2). Assuming 2.5 operations to repair a 154 recurrent retinal detachment further lowers the slope to 312.6 from 2,318.1 cases in 2000 to $7,378.0$ 155 cases in 2018. 
157 During 2000-01 there were 5,761 pars plana vitrectomy procedures carried out and recorded as

158 main intervention. Adding the codes of other surgical manoeuvres recorded as main intervention

159 and which obligatorily required pars plana vitrectomy, the total estimate of pars plana vitrectomy

160 rises to 8,777 . Both figures have increased steadily with a yearly rate of $8.5 \%$ for vitrectomy (slope $=$

$1611,384.1, R^{2}=0.97, p<0.0001$ ) and $6.9 \%$ for the composite of vitrectomy codes (slope=1,363.3,

$\left.162 R^{2}=0.99, p<0.0001\right)$. The final figure for $2017-18$ is 26,900 for vitrectomy coded singly and 29,923 for

163 vitrectomy composite respectively (Figure 3). Similarly, for 2000-01 there were 2,897 scleral buckling

164 operations which decreased steadily at an average yearly rate of $7.0 \%$ to 780 cases with a slope of -

$165114.5\left(R^{2}=0.87, p<0.0001\right)$

\section{Associations}

167 The ratio of scleral buckle operations to RRD admissions changed from 84:100 in 2000-01 to 7.1:100

168 in $2017-18$, at a rate of -0.04 buckling operation per admission for RRD per year. There was a strong

169 and statistically significant correlation between the number of cataract surgery procedures and

170 number of admissions for RRD with breaks $(r=0.932, r 2=0.868, p<0.0001)$. 


\section{Discussion}

172 We found that the frequency of admissions to hospital for the types of retinal detachment which are

173 treated by surgery (both TRD and RRD) increased steadily in England from 2000-2018. During the

174 same period, England's population increased from 49.2 million to 54.3 million, at a proportionally

175 slower rate than that for recorded hospital episodes. It is important to make the distinction between

176 incidence, prevalence and frequency of a disease. As the HES collect episodes, it is not possible to

177 determine neither incidence nor prevalence without obtaining the raw HES data to eliminate

178 duplicates as any episode of care for the same condition will be counted twice. However, given that

179 the methodology of data collection for HES can be assumed to be reasonably constant, trend

180 analysis for defined variables is useful in gaining understanding of the behaviour of healthcare

181 activity.

Rhegmatogenous retinal detachment

There have been several national and regional population studies published over recent years which have estimated the annual incidence of RRD, reporting results ranging from 9.7 to $20.7 / 100,000 /$ year in developed Western and Asian nations ${ }^{1-2,7-14}$. Broadly, two types of methodology were used: hospital records analysis and national reimbursement databases. Hospital records analysis have been reported for defined populations where only a small number of hospitals provide retinal detachment care. Manners ${ }^{7}$ analysed all admissions to Western Australian hospitals between 2000-2013 reporting stable rates between 12.8 and 16.2/100,000 people. Also in Australia, Howie ${ }^{8}$ reported rates for the island-state of Tasmania where a single surgeon provided care between 2005 and 2010, finding a rate of 9.7/100,000 inhabitants. In Scotland ${ }^{9}$, a consortium formed by 6 hospitals prospectively recorded all primary cases between 2007-2009 finding an incidence of 12.05/100,000. A similar consortium formed in the Netherlands ${ }^{10}$ reported 
possible that it also treated patients from outside its reference area. This type of study is better suited to define clinical variables and patient characteristics.

Analysis of national databases have also been reported studying recent years in England ${ }^{1,2}$, Denmark $^{12}$, and Korea ${ }^{13}$. These are more likely to give more accurate estimates and allow to describe time-trends over a period. In England, multiple database linkage analysis was carried out covering the period from 1968 through to 2011. This study also sought to find associations with socioeconomic and health status variables. Analysing the general three-digit code for retinal detachment $\mathrm{H} 33$ without distinction, it estimated that the global incidence of all types of retinal detachments increased from 13.4/100,000 in 1999 to 15.4/100,000 in 2011. A similar nationwide study in Denmark ${ }^{12}$ also found a steady increase of incidence from 2000 to 2011 which they linked to an increase in rates of cataract surgery. The mean incidence over the period was reported at 13.7/100,000. In $\mathrm{Korea}^{13}$, a five-year study covering 2007 to 2011 found an incidence of $10.4 / 100,000$ which remained stable. A further Taiwanese ${ }^{14}$ database covering $4 \%$ of the population reported an estimated incidence of $16.4 / 100,000$ cases from $2000-2012$.

It is quite remarkable that in a period of 18 years, the rate for admissions for RRD in England went from 7.0/100,000 to $19.7 / 100,000$ people. Even when including an estimate for recurrent cases, this represents a steep increase which almost doubles the figure of admissions to 13.7/100,000.

Several risk factors predisposing to RRD have been identified including male gender, increasing age, previous cataract surgery, and myopia. Several of the database studies cited above have found that age is an important risk factor for RRD ${ }^{2,12,14}$. Shah found an almost 20 -fold increased risk of RD in the over 60s age group compared with the under 30s age group ${ }^{2}$. As the average age of England's population increases, so has the average age of admissions for RRD. While male gender is a significant risk factor for RRD, there have been no recent significant changes in the gender composition of England's population ${ }^{5}$. There are no accurate population-wide studies of the prevalence of myopia in England. However, analysis of population cohorts has shown a sustained 
221 worldwide increase in the prevalence of myopia particularly amongst young subjects. This effect is

222 more marked across Asia, Europe and the United States ${ }^{15}$. An eye with a refractive error of more

223 than -3 dioptres has a tenfold increased risk of RD compared to an emmetropic eye ${ }^{9}$. The increase in

224 the number of performed cataract operations can be partly attributed to population aging, and

225 hence a higher prevalence of cataracts. In addition, there has been an inclination to perform cataract

226 surgery at an earlier stage with the advent of phacoemulsification ${ }^{10}$. A review of the literature found

227 that the risk of RD following phacoemulsification is approximately ten times the risk for the general population ${ }^{16}$.

It is interesting to note that the rate of retinal breaks remained relatively constant during the period analysed. This observation is surprising because by definition RRDs occur after retinal tear formation. Therefore if the natural rate of RD was increasing, it could be expected that the rate of retinal tears would also have increase in parallel or faster. A potential explanation for this observation is a proposed catastrophic behaviour of RRD development, where they would form suddenly in "leaps and bounds"17, therefore only low-risk tears would be diagnosed prior to developing into RD. Another potential explanation would be improvements in access to care for patients both by improved referral pathways and by offering surgery to RDs which previously would have been deemed inoperable. Further, we observed that when a correction was introduced to account for estimated rates of recurrent RD, the slope of the growth in RD episodes became less steep. We believe that it is likely that improved instrumentation has led to practitioners persevering in achieving retinal attachment through multiple operations. Operating on recurrent RD would then partially explain the marked increase in HES recorded episodes. It is worth noting that regardless of the incidence of primary RD, a proportion of patients will unfortunately experience RD recurrences. This fact needs to be considered when planning the delivery of service. 
245 In our study we also observed a big increase in TRD admissions. The prevalence of diabetes mellitus

246 increased year on year since 2005-2018 from 3.6\%-5.8\%, which can partly account for the trend we

247 observed ${ }^{18}$. However a group of researchers ${ }^{19}$ found reducing rates of vitrectomy for all indications

248 in diabetic patients in a well-defined geographic area in the North-East of England. They attributed

249 this to better screening and early treatment of proliferative diabetic retinopathy. In recent years,

250 public health intervention on diabetic eye disease in England has been robust, likely reducing the

251 proportion of patients developing severe disease. Therefore as the likelihood of developing TRD for

252 any given patient is decreasing, the number of new diabetics is increasing at a large rate.

253 Additionally, the code for TRD allows for coding cases caused by proliferative vitreo-retinopathy,

254 retinopathy of prematurity and rarer forms of TRD, making it more difficult to analyse diabetes cases

255 in isolation. Another factor which may contribute to explain this increase are improvements in

256 surgical techniques which have resulted in lower thresholds for intervention.

Increase in vitrectomy

We found that the number of reported pars plana vitrectomies irrespective of indication increased

over fourfold between $2000-2018$. When analysing data since the introduction of vitrectomy

surgery, the rate of increase in England was near tenfold up to $2003^{1}$. Advances in surgical

instrumentation, massification of the technology, the introduction of optical coherence tomography

have all contributed to the expanding application of vitrectomy surgery to a larger number of

conditions. Unfortunately, as ICD-10 codes for macular disease make no distinction between

conditions treated medically or surgically, analysis of the data on HES does not help to elucidate changes in rates of macular surgery. 
coincides with significant improvements in operating microscopes and surgical instrumentation, as

well as important advances in surgical techniques and training. A landmark randomised controlled

trial ${ }^{20}$ published in 2007 showed no significant difference in the likelihood of achieving retinal

attachment overall except in pseudophakic eyes where it found an advantage for vitrectomy.

Despite scleral buckling allowing better visual outcomes in phakic eyes, vitrectomies have

overwhelmingly become the preferred surgical strategy for RRD. Presumably the effectiveness,

buckling seems to have stabilised from 2015.

The use of national datasets has the advantage of providing large scale data over a long time span. code "pars plana vitrectomy" as the defining procedure, but another step done during the operation. For this reason, adding OPCS manoeuvres which can only be done as part of a vitrectomy operation gives a higher number, likely to be closer to the true number of vitrectomies carried out. 
admissions in England was likely to be associated with diabetes through linkage analysis with the

Oxford database. There is however no biological plausibility to diabetes leading to an increase in

RRD. As the study used the generic three-digit code for RD (H33), rather than breaking it down into

subcategories (H33.X). We found that both TRD and RRD increased significantly. It is possible that

some RD "with breaks" which should be coded H33.0 may have been coded as H33.4 "tractional RD"

and vice-versa, even if the code for RRD specifically excludes diabetes as an aetiology. Another

limitation of analysing aggregated HES reports is that as episodes are recorded per admission, data analysing administrative data such as England's HES.

In conclusion, the hospital admission rates for all types of RD seem to have increased significantly in recent years, an effect more marked in cases of RRD. This observation is probably attributable to increasing age, rise in the number of performed cataract operations and increase in the prevalence of diabetes for the tractional type of retinal detachment. Other possible explanations may be increased prevalence of myopia, changes in methodology of hospital coding, improvements in patient access and public awareness, increased repeated procedures, and lower thresholds for 
medRxiv preprint doi: https://doi.org/10.1101/2020.11.06.20214734; this version posted November 7, 2020. The copyright holder for this preprint (which was not certified by peer review) is the author/funder, who has granted medRxiv a license to display the preprint in perpetuity. It is made available under a CC-BY-NC-ND 4.0 International license.

\section{Conflict of Interest}

319 The authors declare no potential of conflicts of interest with respect to the research, authorship,

320 and/or publication of this article.

\section{$321 \quad$ Funding}

322 The authors received no financial support for the research, authorship, and/or publication of this

323 article. 


\section{References}

1. El-Amir AN, Keenan TD, Abu-Bakra M, Tanner V, Yeates D, Goldacre MJ. Trends in rates of retinal surgery in England from 1968 to 2004: studies of hospital statistics. Br J Ophthalmol. 2009;93(12):1585-90.

2. Shah V, Hall N, Goldacre MJ. Retinal detachment in England: database studies of trends over time and geographical variation. Br J Ophthalmol. 2015;99(5):639-43

3. Li JQ, Welchowski T, Schmid M, Holz FG, Finger RP. Incidence of Rhegmatogenous Retinal Detachment in Europe - A Systematic Review and Meta-Analysis. Ophthalmologica. 2019;242(2):81-86.

4. NHS Digital. https://digital.nhs.uk/data-and-information/data-tools-and-services/dataservices/hospital-episode-statistics [Accessed $2^{\text {nd }}$ May 2020].

5. Office for National Statistics. http://www.ons.gov.uk [Accessed on $3^{\text {rd }}$ May 2020].

6. Jackson TL, Donachie PH, Sallam A, Sparrow JM, Johnston RL. United Kingdom National Ophthalmology Database study of vitreoretinal surgery: report 3, retinal detachment. Ophthalmology. 2014 Mar;121(3):643-8.

7. Manners S, Ng JQ, Kemp-Casey A, Chow K, Kang CY, Preen DB. Retinal detachment surgery in Western Australia (2000-2013): a whole-population study. Br J Ophthalmol. 2017;101(12):1679-1682.

8. Howie AR, Darian-Smith E, Allen PL, Vote BJ. Whole population incidences of patients presenting with rhegmatogenous retinal detachments within Tasmania, Australia. Clin Exp Ophthalmol. 2016;44(2):144-6.

9. Mitry D, Charteris DG, Yorston D, Siddiqui MA, Campbell H, Murphy AL et al; Scottish RD Study Group. The epidemiology and socioeconomic associations of retinal detachment in Scotland: a two-year prospective population-based study. Invest Ophthalmol Vis Sci. 2010;51(10):4963-8. 
10. Van de Put MAJ, Hooymans JMM, Los LI; Dutch Rhegmatogenous Retinal Detachment Study

Group. The incidence of rhegmatogenous retinal detachment in The Netherlands. Ophthalmology. 2013;120(3):616-622.

11. Poulsen CD, Peto T, Grauslund J, Green A. Epidemiologic characteristics of retinal detachment surgery at a specialized unit in Denmark. Acta Ophthalmol. 2016;94(6):548-55.

12. Hajari JN, Bjerrum SS, Christensen U, Kiilgaard JF, Bek T, la Cour M. A nationwide study on of the fellow eye. Retina. 2014;34(8):1658-65.

13. Park SJ, Choi NK, Park KH, Woo SJ. Five year nationwide incidence of rhegmatogenous retinal detachment requiring surgery in Korea. PLoS One. 2013;13;8(11):e80174. the incidence of rhegmatogenous retinal detachment in Denmark, with emphasis on the risk 14. Chen SN, Lian leB, Wei YJ. Epidemiology and clinical characteristics of rhegmatogenous retinal detachment in Taiwan. Br J Ophthalmol. 2016;100(9):1216-20.

15. Williams KM, Bertelsen G, Cumberland P, Wolfram C, Verhoeven VJ, Anastasopoulos E et al; European Eye Epidemiology (E(3)) Consortium. Increasing Prevalence of Myopia in Europe and the Impact of Education. Ophthalmology. 2015;122(7):1489-97.

16. Qureshi MH, Steel DHW. Retinal detachment following cataract phacoemulsification-a review of the literature. Eye (Lond). 2020 Apr;34(4):616-631.

17. Lakawicz JM, Bottega WJ, Prenner JL, Fine HF. An analysis of the mechanical behaviour of a detaching retina. Math Med Biol. 2015 Jun;32(2):137-61.

18. Diabetes UK Consortium. Available from: http://www.diabetes.org.uk [Accessed $3^{\text {rd }}$ May 2020].

19. Vaideanu D, Sandhu SS, Ling J, Richardson J, Steel DH. Rate of diabetic vitrectomy in a defined geographical part of North East England. Ophthalmic Epidemiol. 2014;21(3):178-83.

20. Heimann H, Bartz-Schmidt KU, Bornfeld N, Weiss C, Hilgers RD, Foerster MH; Scleral Buckling versus Primary Vitrectomy in Rhegmatogenous Retinal Detachment Study Group. Scleral 
medRxiv preprint doi: https://doi.org/10.1101/2020.11.06.20214734; this version posted November 7, 2020. The copyright holder for this preprint (which was not certified by peer review) is the author/funder, who has granted medRxiv a license to display the preprint in perpetuity. It is made available under a CC-BY-NC-ND 4.0 International license.

375 buckling versus primary vitrectomy in rhegmatogenous retinal detachment: a prospective

376 randomized multicenter clinical study. Ophthalmology. 2007;114(12):2142-54.

377

21. Sinha S, Peach G, Poloniecki JD, Thompson MM, Holt PJ. Studies using English administrative data (Hospital Episode Statistics) to assess health-care outcomes--systematic review and recommendations for reporting. Eur J Public Health. 2013 Feb;23(1):86-92. 
medRxiv preprint doi: https://doi.org/10.1101/2020.11.06.20214734; this version posted November 7, 2020. The copyright holder for this preprint

(which was not certified by peer review) is the author/funder, who has granted medRxiv a license to display the preprint in perpetuity.

It is made available under a CC-BY-NC-ND 4.0 International license.

380

Figure Legends

$381 \quad$ Figure 1: Completed consultant episodes at hospitals in England for retinal detachment codes

$382 \quad H 33 . x, 2000-2018$.

383

Figure 2: Hospital admissions for retinal detachment and deduction of RD recurrence estimate

384

by mid-year population in England 2000-2018.

385

Figure 3: Number of recorded pars plana vitrectomy procedures and composite of vitrectomy

386 and associated manoeuvres.

387

Figure 4: Ratio of admissions for retinal detachment episodes and composite scleral buckle

388

operations. 
medRxiv preprint doi: https://doi.org/10.1101/2020.11.06.20214734; this version posted November 7, 2020. The copyright holder for this preprint

(which was not certified by peer review) is the author/funder, who has granted medRxiv a license to display the preprint in perpetuity. It is made available under a CC-BY-NC-ND 4.0 International license .

\section{Completed consultant episodes at hospitals in England for retinal detachment codes H33.x, 2000-2018}

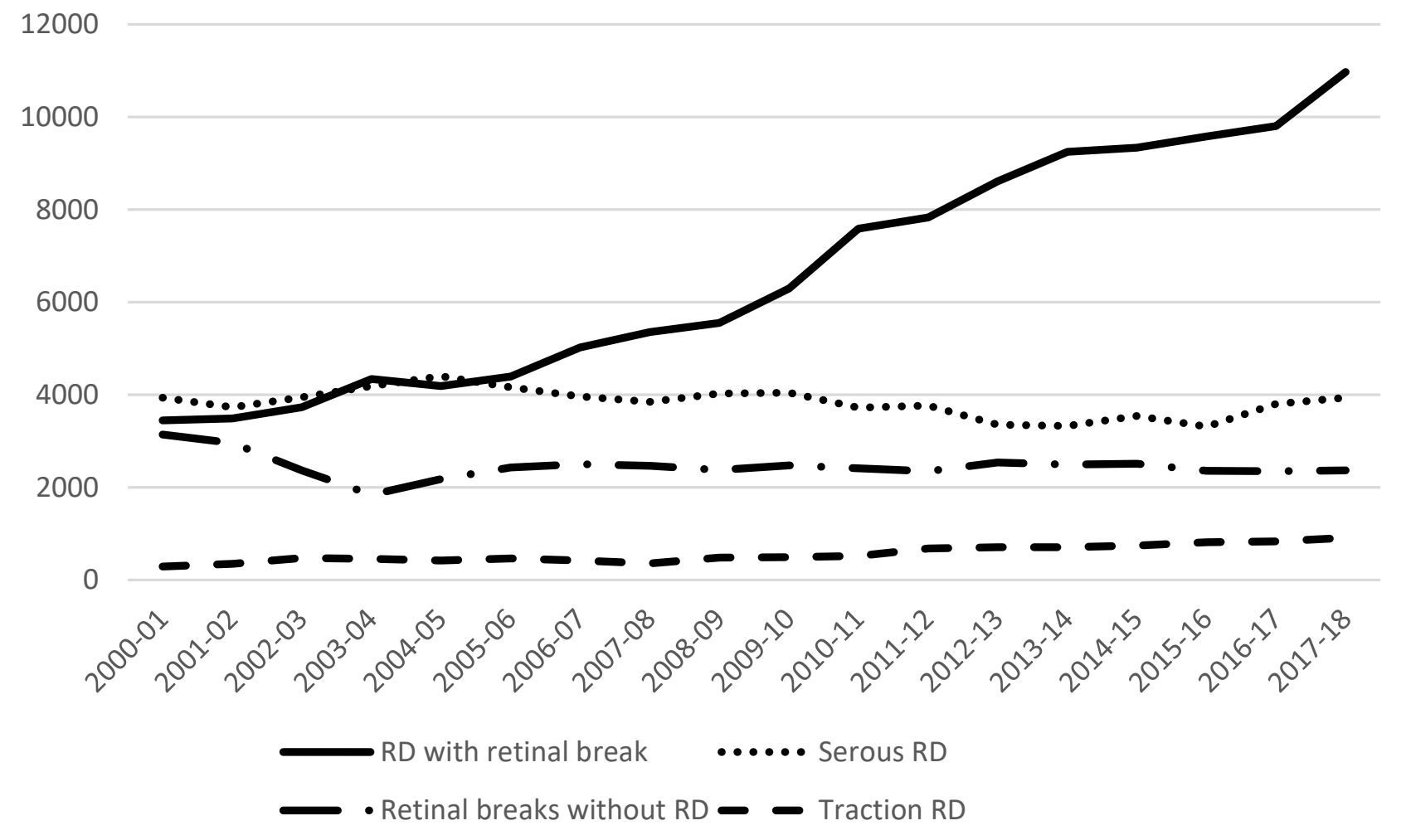


medRxiv preprint doi: https://doi.org/10.1101/2020.11.06.20214734; this version posted November 7, 2020. The copyright holder for this preprint (which was not certified by peer review) is the author/funder, who has granted medRxiv a license to display the preprint in perpetuity. It is made available under a CC-BY-NC-ND 4.0 International license .

\section{Rate of consultant episodes for retinal detachment and deduction of recurrences by mid-year population in England, 2000-18}

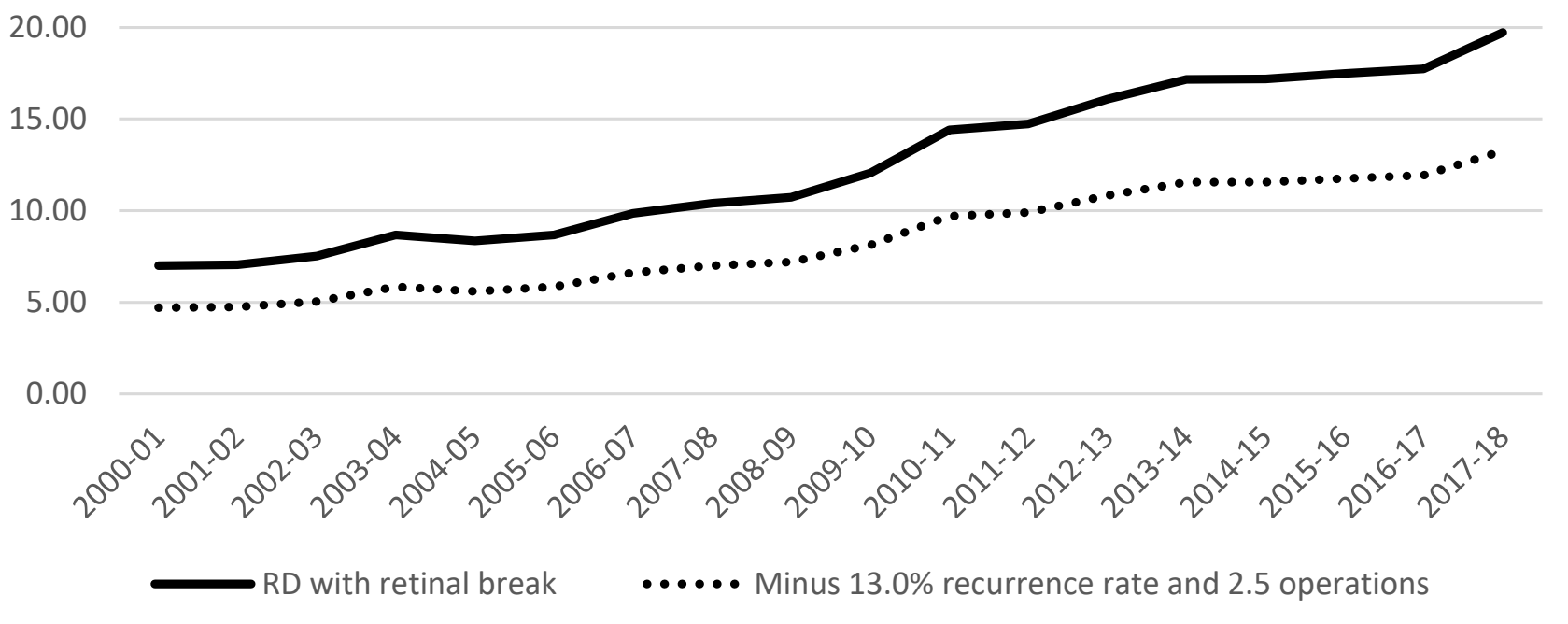


medRxiv preprint doi: https://doi.org/10.1101/2020.11.06.20214734; this version posted November 7, 2020. The copyright holder for this preprint

(which was not certified by peer review) is the author/funder, who has granted medRxiv a license to display the preprint in perpetuity.

It is made available under a CC-BY-NC-ND 4.0 International license.

\section{Number of recorded pars plana vitrectomy procedures and composite of vitrectomy and associated manoeuvres}

35000

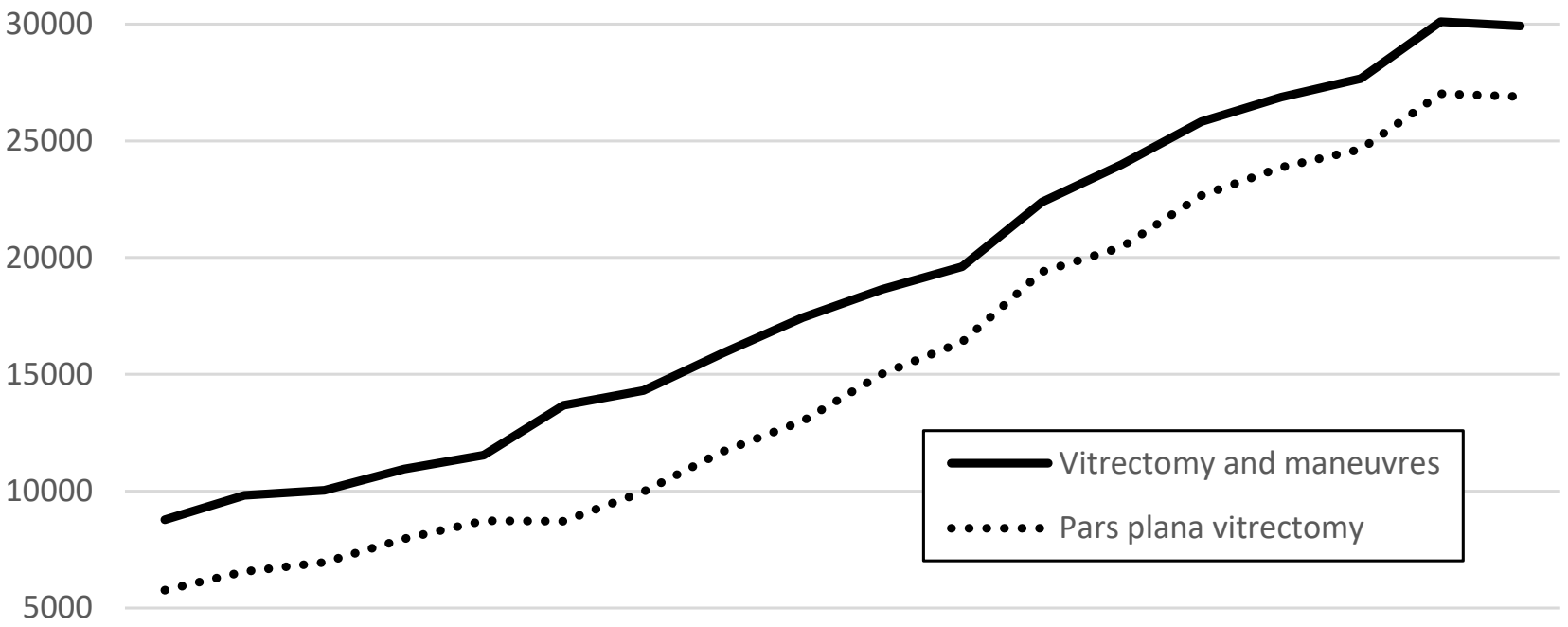

0

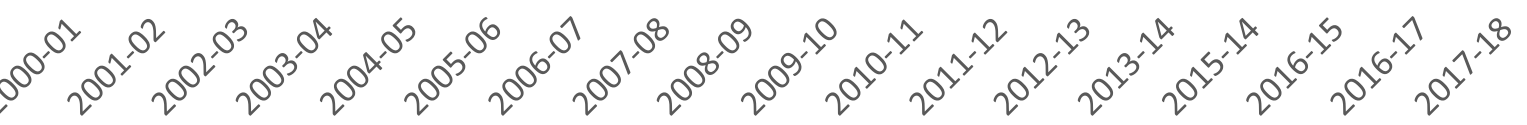


medRxiv preprint doi: https://doi.org/10.1101/2020.11.06.20214734; this version posted November 7, 2020. The copyright holder for this preprint (which was not certified by peer review) is the author/funder, who has granted medRxiv a license to display the preprint in perpetuity. It is made available under a CC-BY-NC-ND 4.0 International license .

\section{Ratio of admissions for retinal detachment episodes and composite scleral buckle operations}

0.9
0.8
0.7
0.6
0.5
0.4
0.3
0.2
0.1
0

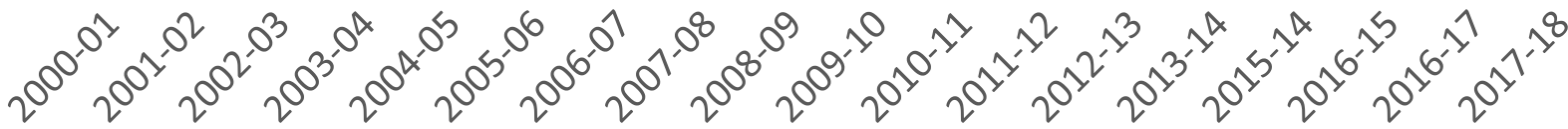

